\title{
LACTATE DEHYDROGENASE ISOENZYMES IN TRANSECTED NERVES*
}

\author{
Reinhard L. Friede and Mechthilde KNOLler \\ Mental Health Research Institute and Department of Pathology, The University of Michigan, \\ Ann Arbor, Michigan
}

(Received 7 November 1963)

THE recent interest in organ-specific patterns of lactate dehydrogenase (LDH) isoenzymes (WIELAND and PFLeiderer, 1957; WrobleWsKI, Ross and Gregory, 1960; PlagemanN, Gregory and Wroblewski, 1960; Wroblewski and Gregory, 1961) stimulated search for isoenzyme pattern differences among regions of the brain. VAN DER HELM (1962) found no isoenzymic differences among several regions of the human brain. LoWENTHAL, VAN SANDE and KARCHER $(1961,1962)$ observed very similar patterns of LDH isoenzymes in grey and white matter, but they observed three different patterns among 15 regions in the brains of man and cat; similar data were obtained by BONAVITA and GUARNERI (1963). LOWENTHAL and co-workers also reported that the LDH isoenzyme patterns in birds and fish were markedly different than those in mammals. PFLeiderer and WACHSMUTH (1961) described differences between cerebellar and cerebral LDH isoenzyme patterns. Marked changes of isoenzyme patterns were noted during development of the brain (Flexner, FlexNer, Roberts and de la Haba, 1960; Pfleiderer and Wachsmuth, 1961; Bonavita, Ponte and Amore, 1962; Gerhardt, Clausen and Anderson, 1963).

This paper reports on the different isoenzyme patterns in the following samples of cat sciatic nerve: (1) the proximal stump of a transected nerve in which most of the enzyme was in swollen axon stumps, (2) a segment of nerve proximal to the first sample, containing no swollen axons, and in which the enzyme was distributed mostly in Schwann cells, (3) a segment of the distal part of the transected nerve in which nearly all of the enzyme was in proliferating Schwann cells, and (4) a sample of the normal contralateral nerve. We also give a simplified method for separation and measurement of isoenzyme fractions; this method, in our hands, was faster and gave better results than several other methods tested.

\section{MATERIALS AND METHODS}

Preparations of Samples. Eleven cats were anaesthesized with sodium pentobarbitone or ether, and with a scalpel the right sciatic nerve was severed proximal to its branching. All surgery was done under antiseptic conditions. The cats were sacrificed 3 or 4 days after the operation and both sciatic nerves were removed. Sample 1 was the proximal stump of the severed nerve; sample 2 was taken proximal to sample 1; the third sample was taken about $4-5 \mathrm{~mm}$ distal to the stump of the distal portion of the severed nerve; sample 4 was taken proximal to the branching of the non-severed contralateral nerve. Immediately after removal, the samples were carefully freed of connective tissue and epineural sheath and weighed. Sample weight ranged from $20-40 \mathrm{mg}$. Homogenization was done by hand in Misco all-glass tissue grinders. $\dagger$ The homogenates, which contained $300 \mathrm{mg}$

* This study has been supported by the U.S. Public Health Grant B 3250.

$\uparrow$ Microchemical Specialities Company, Berkeley 3, California.

Abbreviations used: LDH, lactate dehydrogenase; INT, iodonitrotetrazolium; Nitro BT nitro blue tetrazolium. 
of tissue per $\mathrm{ml}$ of ice-cold physiological $\mathrm{NaCl}$, were stored in ice until use. Samples were always used within $6 \mathrm{hr}$ after death of the animal. Samples tested after $24 \mathrm{hr}$ storage in saline at $4^{\circ}$ did not show any change of pattern nor was there loss of total activity; this agreed with the observations by ZONDAG (1963).

Electrophoresis. Sepraphore III cellulose acetate strips, $1 \times 6.75$ in. were used as supporting medium. A buffer of the following composition was used in the electrophoresis chamber and also for soaking the cellulose acetate strips: sodium diethyl barbituric acid, $10.3 \mathrm{gm}$; diethylbarbituric acid, $2.6 \mathrm{gm}$; tris, $6 \cdot 1 \mathrm{gm} ; \mathrm{H}_{2} \mathrm{O}$ to make $1000 \mathrm{ml}$; $\mathrm{pH}$ was 8.85 . The strips were usually soaked overnight and never less than $3 \mathrm{hr}$; immediately before electrophoresis they were blotted individually between filter paper. A Spinco sample applicatort was used to apply about $5 \mu \mathrm{l}$ of homogenate 2 in. from one end of the strip. Whole homogenates were applied and gave consistent results, contrary to some observations in the literature. A straight, narrow, and uniform application was essential for good separation; even slight differences of concentration along the line of application caused trailing or distortion of the electrophoretic bands. During electrophoresis, the horizontal strips were held taut with microslides at each end. Five to eight strips were run simultaneously. Current was applied as soon as possible after application, with a voltage gradient of $13 \mathrm{v} / \mathrm{cm}$ along the membranes for 90 min. Runs were made at room temperature and the temperature in the electrophoresis chamber never exceeded $1^{\circ}$ above room temperature. Immediately following electrophoresis, the strips were incubated for $30 \mathrm{sec}$ at $37^{\circ}$ in $\mathrm{LDH}$ substrate mixture containing: $5 \mathrm{ml}$ sodium lactate, $\neq 0.5 \mathrm{M} ; 4 \mathrm{ml}$ $\mathrm{NAD}, \S 0.01 \mathrm{M} ; 6 \mathrm{ml}$ INT $\|$ or Nitro $\mathrm{BT}, \| 2 \mathrm{mg} / \mathrm{ml} ; 5.5 \mathrm{ml}$ glass distilled $\mathrm{H}_{2} \mathrm{O}$. The mixture was adjusted to $\mathrm{pH} 7.3$ with tris-barbital buffer. Immediately before incubation, $0.5 \mathrm{ml}$ of phenazinemethosulphate, $\ddagger 2 \mathrm{mg} / \mathrm{ml}$, was added. Within $30 \mathrm{sec}$ of incubation at $37^{\circ}$ the INT or Nitro BT formazan was clearly visible at the sites of LDH fractions. INT was used whenever spectrophotometric measurements were desired because of the solubility of INT formazan which has been used in this laboratory for quantitative histochemistry (FRIEDE, FLEMING and KNOLLeR, 1963). Longer incubation times did not appear to increase the formazan intensity in the bands but resulted in uneven background staining ('nothing dehydrogenase') which had to be avoided in extraction for spectrophotometric measurements. After a 5 min wash in water, the strips were dried. The distance between bands was about $6 \mathrm{~mm}$, the length of the total pattern was $4 \mathrm{~cm}$ from the starting point. The isoenzyme bands were identified by numbers $I$ to V, I representing the fastest moving component. The five bands of the LDH isoenzyme pattern were spaced equidistantly, thus cutting the zymograph exactly in the middle between the stained LDH fractions and giving five equal sized segments. The segments were dissolved in $1 \mathrm{ml}$ of ethyl acetate within $1 \mathrm{~min}$. A sixth unstained cellulose acetate segment of equal size, adjacent to the most distant band, served as a blank for the spectrophotometric readings. The optical density was determined at $490 \mathrm{~m} \mu$ on a Beckman DU spectrophotometer, and the amount of formazan present in each band was expressed as a percentage value of the total amount of the isoenzyme pattern. Four electrophoretic separations and measurements were done for each sample. On control strips, incubated in medium without $\mathrm{Na}$ lactate, only fraction I was faintly visible. A control strip incubated in medium without NAD showed a faint fraction I, the other four fractions were barely visible. BARNETT (1962) observed substantial reaction in controls, but his incubation time was $1 \mathrm{hr}$.

For histochemical preparations, $30 \mu$ sections of formalin-fixed tissue $\left(4^{\circ}, 24 \mathrm{hr}\right.$ ), were incubated in the medium of ALLEN and SLATER (1961); a more complete account of the method was given in a previous paper (FrIEDE, Fleming and KNOLLER, 1963). Only one cat was used for histochemical staining concurrent with the electrophoretic experiments because numerous sections of transected sciatic nerves, available from previous histochemical studies (FrIEDE, 1959, 1964), established the consistency of the changes of distribution of $\mathrm{LDH}$ in transected nerves.

\section{RESULTS AND DISCUSSION}

\section{Measurements of $\mathrm{LDH}$ isoenzyme fractions in the sciatic nerves}

The reproducibility of the isoenzyme patterns is good (Table 1). Two additional cats showed identical patterns but were processed with Nitro BT and not measured spectrophotometrically (Fig. 1). Figure 2 summarizes the data in Table 1. The three samples of transected nerve had different isoenzyme patterns and all were different from that of the contralateral normal nerve, but the proximal stump sample

* Gelman Instrument Company, 600 S, Wagner Rd., Ann Arbor, Michigan.

$\uparrow$ Spinco Division of Beckman Instruments, Incorporated, Palo Alto, California.

¥ Sigma Chemical Company, St. Louis, Missouri.

§ California Corporation of Biochemical Research, Los Angeles, California.

Dajac Laboratories, 5000 Langdon St., Philadelphia 24, Pennsylvania. 


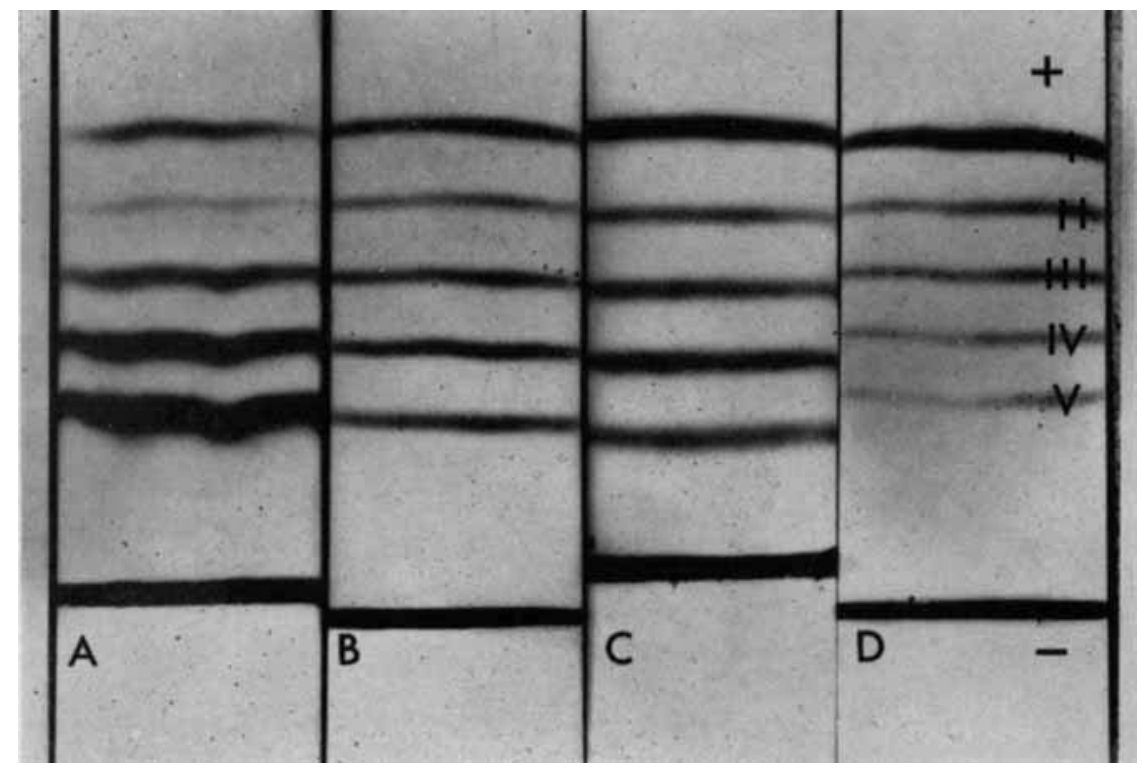

FIG. 1.-Electrophoretic separation of LDH isoenzymes in various samples of the sciatic nerve of one single cat: (A) proximal stump; (B) proximal to proximal stump; (C) distal sample and (D) normal contralateral stump. The lowermost band represents the zone of application.

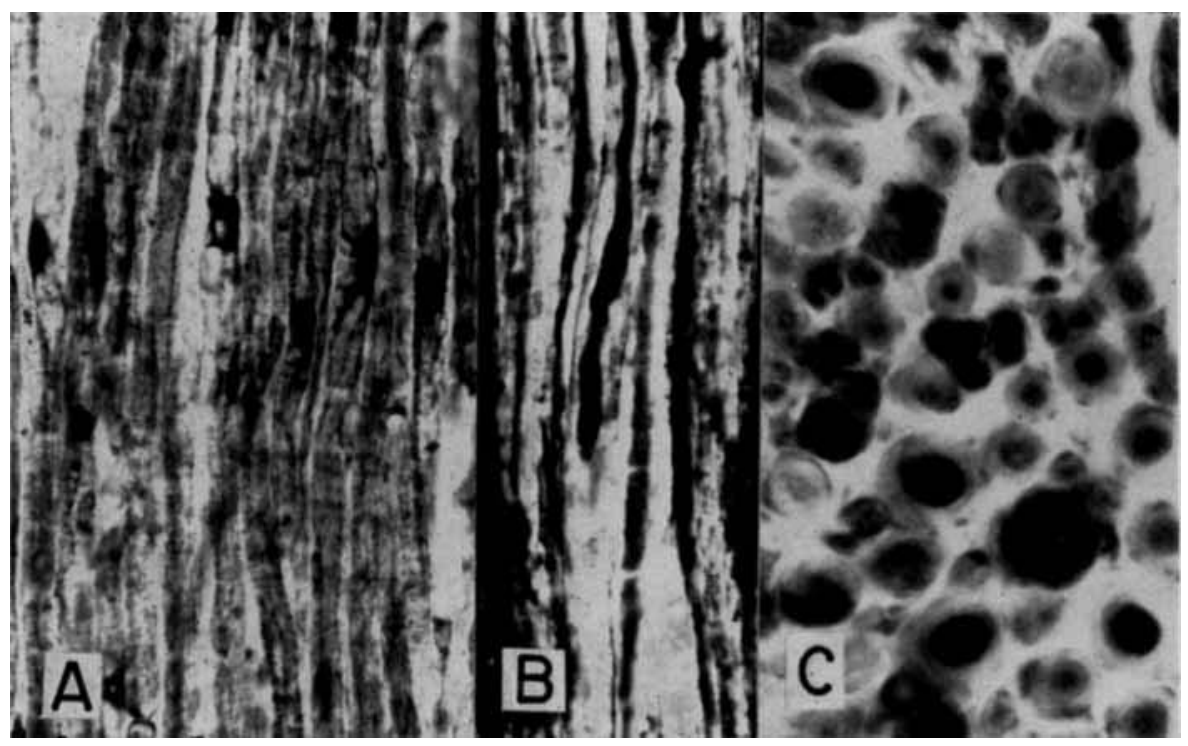

FIG. 3.- Histochemical distribution of LDH: (A) distal sample; most of the LDH is in Schwann cells and their processes. (B) and (C) proximal stump; most of the LDH is in extremely dilated axons. (B) represents a longitudinal section, (C) a transverse section at high power, demonstrating the myelin sheath, without reaction, surrounding the intensely reacting swollen axons. 


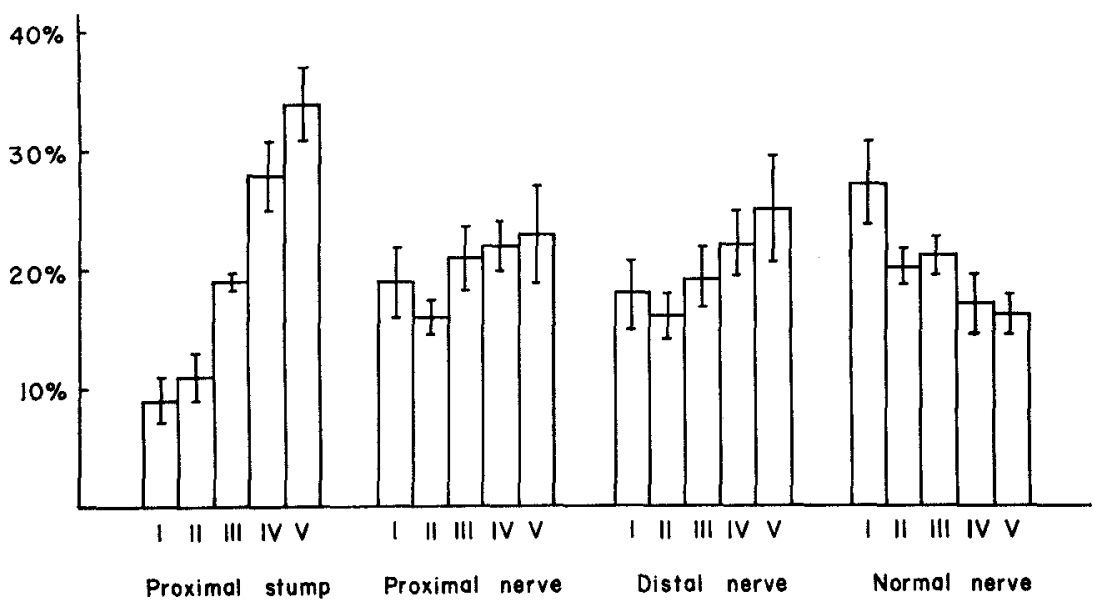

FIG. 2.--Average isoenzyme patterns for all eight cats, expressed as percentage values of the total amount of formazan extracted for each given sample.

TABLE 1.-LACTATE DEHYDROGENASE ISOENZYME FRACTIONS IN TRANSECTED NERVES

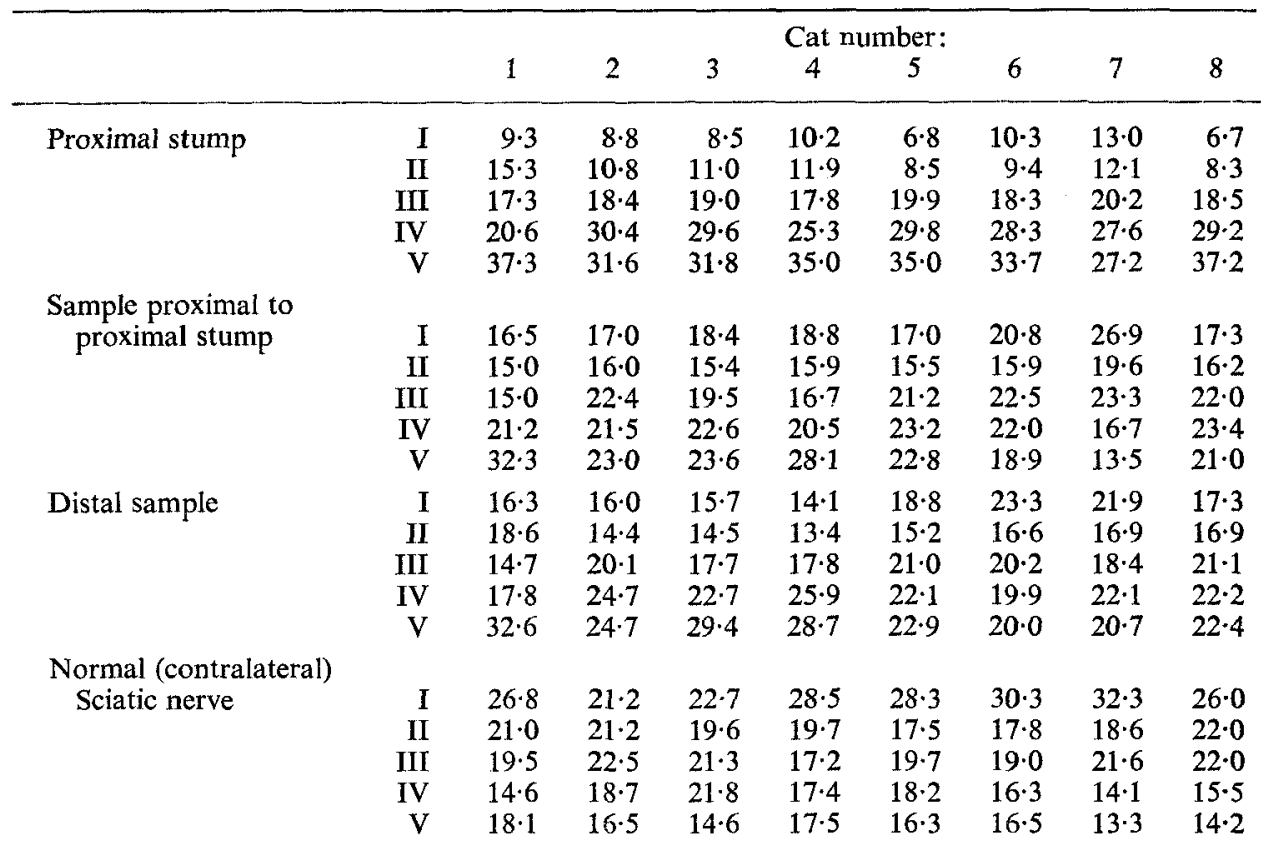

Measurements are expressed as percentage values, for each band, of the total amount of formazan extracted from the zymogram. Each value is an average of four electrophoretic determinations. 
showed by far the most striking changes in concentration of LDH isoenzyme fractions. From previous experiments on rats, we know that there is a cytological redistribution of oxidative enzyme activity during the first week following transection or constriction of a peripheral nerve (FRIEDE, 1959). The histochemical preparations in this series also showed a marked increase of $\mathrm{LDH}$ and several other oxidative enzymes in the proximal stumps of transected axons on the 4th day. Farther proximal to the stump, and also in the distal segment of the nerve, where Wallerian degeneration occurred, enzymic activity was mostly in Schwann cells and a small fraction was in blood vessels (Fig. 3). Therefore, it could be assumed that the proximal stump isoenzyme pattern was mostly axonal and that the patterns of the other two samples represented mostly Schwann cell LDH.

The LDH isoenzyme pattern of Schwann cells (or proliferating Schwann cells) was very different from that of 'swollen axons'. Since any combination of the Schwann cell plus the axonal pattern did not resemble the isoenzyme pattern of normal nerve, it appears that some, if not all, of the isoenzyme pattern differences were due to cellular injury response. Obviously a new approach is needed to demonstrate the normal isoenzyme pattern individually for axons and for Schwann cells.

\section{SUMMARY}

Studies of lactate dehydrogenase isoenzymes in transected cat sciatic nerve showed marked changes of the isoenzyme distribution in the various portions of the severed nerve. The resulting patterns were tentatively correlated with the distribution of swollen axons and Schwann cells, respectively.

\section{REFERENCES}

ALLEN J. M. and Slater J. J. (1961) J. Histochem. Cytochem. 9, 221.

BARNETT H. (1962) Biochem. J. 84, 83P.

Bonavita V., Ponte F. and Amore G. (1962) Nature (Lond.) 196, 567.

BONAVITA V. and GuARneri R. (1963) Naturwissenschaften 50, 597.

FrIEde R. L. (1959) Exp. Neurol. 1, 441.

Friede R. L., Fleming L. M. and Knoller M. (1963) J. Histochem. Cytochem. 11, 232.

Friede R. L. (1964) Acta Neuropath. (Berl.) 3, 229.

Flexner L., Flexner J., Roberts R. and de la Haba G. (1960) Develop. Biol. 2, 313.

Gerhardt W., Clausen J. and ANDerson H. (1963) Acta neurol. scand. 39, 31.

VAN DER HELM H. J. (1962) J. Neurochem. 9, 325.

Lowenthal A., van Sande M. and Karcher D. (1961) Ann. N.Y. Acad. Sci. 94, 988.

Lowenthal A., van Sande M. and KarCHer D. (1962) Arch. int. Physiol. 70, 420.

Pfleiderer G. and Wachsmuth E. D. (1961) Biochem. Z. 334, 185.

Plagemann P. G. W., Gregory K. F. and Wroblewski F. (1960) J. biol. Chem. 235, 2282.

Wieland T. and Pfleiderer G. (1957) Biochem. Z. 329, 112.

Wroblewski F. and Gregory K. F. (1961) Ann. N.Y. Acad. Sci. 94, 912.

Wroblewski F., Ross C. and Gregory K. F. (1960) New Engl. J. Med. 263, 531.

ZONDAG H. A. (1963) Science 142, 965. 